\title{
TRIPLE INNOMINATE OSTEOTOMY FOR HIP STABILISATION AND TRANSILIAC LEG LENGTHENING AFTER POLIOMYELITIS
}

DUK YONG LEE, IN HO CHOI, CHIN YOUB CHUNG, JAE HOON AHN, HOWARD H. STEEL

From Seoul National University Hospital, Seoul, South Korea and Shriners Hospital for Crippled Children, Philadelphia, USA

We reviewed our experience with a modified triple innominate osteotomy for hip instability and limb shortening due to poliomyelitis in 62 adolescent and adult patients, treated from 1973 to 1990 . Their ages at surgery ranged from 12 years to 35 years (average 22.3).

At a mean follow-up of 4 years (2 to 18) 59 of the patients $(95.2 \%)$ had substantial improvement in hip stability, and all but one had radiological improvement as determined by the acetabular angle, centre-edge angle and acetabulum-head quotient. In 59 cases in which transiliac limb lengthening was attempted, the mean gain was $1.7 \mathrm{~cm}$ (0.6 to 3.0). When the abductor muscles had been partially paralysed, the operation produced an appreciable increase in power in 12 of the 39 hips examined.

J Bone Joint Surg [ Br] 1993: 75-B :858-64.

Receiced II January 1993; Accepted 29 April 1993

Deformity of the hip is common in patients after poliomyelitis, and is initially due to muscle imbalance, faulty posture, and the absence of normal weight-bearing stimulation. When deformity is associated with pelvic obliquity and limb shortening, subluxation or even dislocation may occur (O'Brien, Dwyer and Hodgson 1975). Pelvic osteotomy with or without associated softtissue procedures may be necessary to prevent these complications.

In older children and young adults secondary paralytic acetabular dysplasia cannot be satisfactorily corrected by either the Salter or the Pemberton osteotomy.

D. Y. Lee, Professor and Director of The Children's Hospital I. H. Choi, MD, Associate Professor

C. Y. Chung, MD, Instructor

J. H. Ahn, MD, Chief Resident

Department of Orthopaedic Surgery, Seoul National University Hospital, 28 Yungun-dong, Chongro-ku, Seoul 110-744, South Korea.

H. H. Steel, MD, Emeritus Chief of Staff

Shriners Hospital for Crippled Children, 8400 Roosevelt Boulevard, Philadelphia, Pennsylvania 19152, USA.

Correspondence should be sent to Professor D. Y. Lee.

(C) 1993 British Editorial Society of Bone and Joint Surgery

$0301-620 \mathrm{X} / 93 / 6664 \$ 2.00$
This has led several authors to devise triple pelvic osteotomies that allow greater rotation of the acetabular fragment and make possible a more effective correction of the dysplasia (LeCoeur 1965; Hopf 1966; Steel 1973; Tönnis 1982).

The redirectional pelvic osteotomy of Steel (1973) divides the ischial ramus, the superior pubic ramus, and the ilium above the acetabulum and allows the acetabulum to be rotated anterolaterally. This operation is technically simpler, safer and just as effective as the periacetabular osteotomies reported by others (Eppright 1975; Wagner 1976; Kawamura, Hosono and Yokogushi 1982; Ninomiya and Tagawa 1984).

Transiliac leg lengthening was reported by Millis and Hall (1979) and Barry, McManus and O'Brien (1992), who used a modified Salter innominate osteotomy, usually for non-paralytic conditions. We have performed Steel's triple innominate osteotomy for paralytic hips with dysplasia and instability in both adolescent and adult patients after poliomyelitis. Leg lengthening was not the prime purpose of the osteotomy, but gain in length provided an additional advantage (Lee 1984).

There are few reports of the results of triple innominate osteotomy for acetabular dysplasia after poliomyelitis. Steel (1977) described 18 such cases in a total of 175 osteotomies. Lau et al (1986) reported the results of various pelvic osteotomies for this type of case including four in which Steel's osteotomy was used.

We now report the results of Steel's osteotomy for hip stabilisation and transiliac limb lengthening in 62 patients with unstable hips and limb shortening due to poliomyelitis.

\section{PATIENTS AND METHODS}

From December 1973 to August 1990 at the Seoul National University Hospital, Korea, we treated 80 hips in 78 patients after poliomyelitis. Their ages were from 12 to 35 years (average 22.3). All patients had hip instability and had the triple innominate osteotomy and ancillary soft-tissue procedures as necessary. Of these, 62 hips in 62 patients had clinical records and radiographs for detailed review. There were 15 males and 47 females 


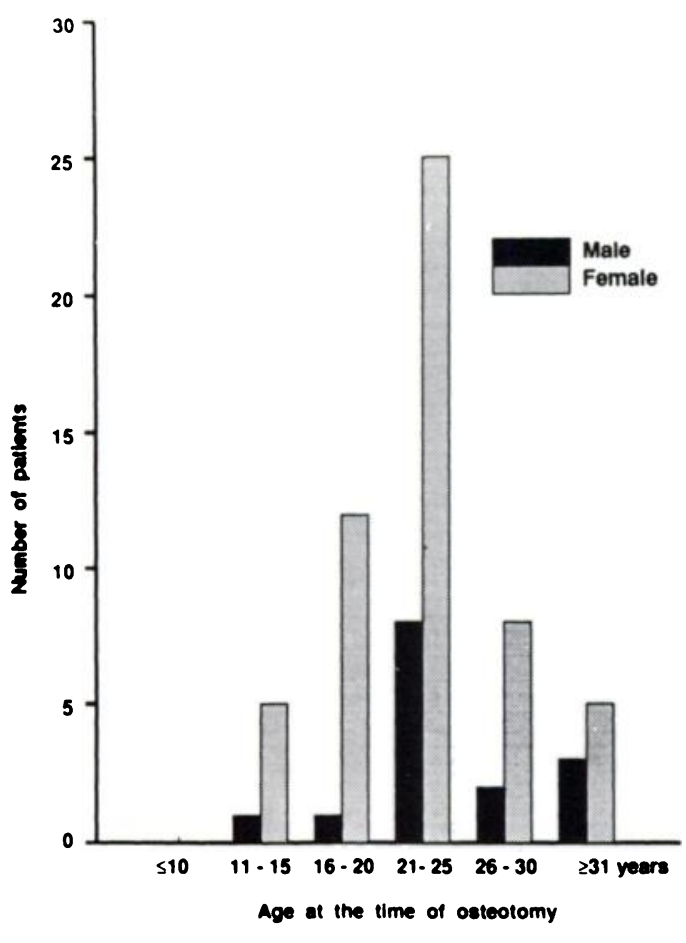

Fig. 1

Age and sex distribution of 62 patients who underwent triple osteotomy after poliomyelitis.

(Fig. 1) who were followed for an average of 4 years 1 month after the operation ( 2 years to 18 years 3 months). Triple innominate osteotomy. The surgical approach was that described by Steel (1973), but when transiliac lengthening was indicated, the iliac osteotomy was opened posteriorly as well as anteriorly, and a trapezoidal, rather than a triangular bone graft was inserted into the opening. The iliopsoas tendon did not usually need division, because of its attenuation due to paralysis.

Our indications for triple innominate osteotomy in these cases were:

Hip instability. Paralytic hip instability has been classified by the senior author (DYL) into 5 grades (Table I, Fig. 2).
The major factors contributing to instability are the patient's age, weight-bearing capability, degree of motor paralysis, pelvic obliquity, and limb shortening.

Lower limb shortening. The limb of the side on which the hip is unstable is usually, but not always, short, either anatomically or functionally. When there was shortening, an effort was made to lengthen the pelvis at the time of the osteotomy, particularly if there was fixed pelvic obliquity and elevation of the ipsilateral pelvis. When limb shortening is only 2 to $3 \mathrm{~cm}$, transiliac lengthening can produce complete equalisation, or at least reduce the discrepancy to the acceptable level of less than $1 \mathrm{~cm}$. When triple innominate osteotomy is planned for hip instability and it is considered that femoral lengthening will be required later, the addition of transiliac lengthening to the first procedure can reduce the femoral lengthening needed and thereby decrease the morbidity of the second procedure.

Associated operations. Any necessary soft-tissue correction of deformity usually preceded the triple osteotomy. These procedures included lumbodorsal fasciotomy for fixed pelvic obliquity (Ha et al 1972). Releases for ipsilateral hip adduction contracture or contralateral abduction contracture were performed either before or at the time of triple osteotomy. Abductor or abductorextensor reconstruction when needed was performed either at the time of, or sometimes after, the pelvic osteotomy (Table II).

When the pelvic osteotomy and any soft-tissue procedures had healed, any length inequality was evaluated with the patient standing. When equalisation was indicated and the hip was stable, femoral lengthening was performed.

Assessment of results. We assessed the results by four criteria:

1) the grade of instability;

2) various radiological indices;

3) the transiliac lengthening that had been achieved; and

4) abductor muscle strength.

Hip instability (Table I, Fig. 2). We attempted to grade

Table I. Classification of instability of paralytic hips

\begin{tabular}{lll}
\hline Grade & Clinical & Radiological \\
\hline 0 Normal & Stable & $\begin{array}{l}\text { Concentric, congruous joint } \\
\text { Normal acetabular angle }\end{array}$ \\
I Hypermobile & $\begin{array}{l}\text { Increased hip motion } \\
\text { No telescoping }\end{array}$ & $\begin{array}{l}\text { Medial joint-space widening } \\
\text { Normal acetabular angle }\end{array}$ \\
II Subluxatable & Mild telescoping & $\begin{array}{l}\text { Subluxatable on push view or weight-bearing } \\
\text { view } \\
\text { Acetabular angle normal or slightly increased }\end{array}$ \\
III Subluxated & Moderate telescoping & $\begin{array}{l}\text { Subluxation on supine view } \\
\text { Dysplastic acetabulum }\end{array}$ \\
IV Dislocatable & $\begin{array}{l}\text { Marked telescoping } \\
\text { Exit click }\end{array}$ & $\begin{array}{l}\text { Subluxation on supine view } \\
\text { Dislocatable on push view } \\
\text { False acetabulum may be present }\end{array}$ \\
V Dislocated & Marked telescoping & $\begin{array}{l}\text { Frank dislocation } \\
\text { Usually irreducible }\end{array}$ \\
\hline
\end{tabular}



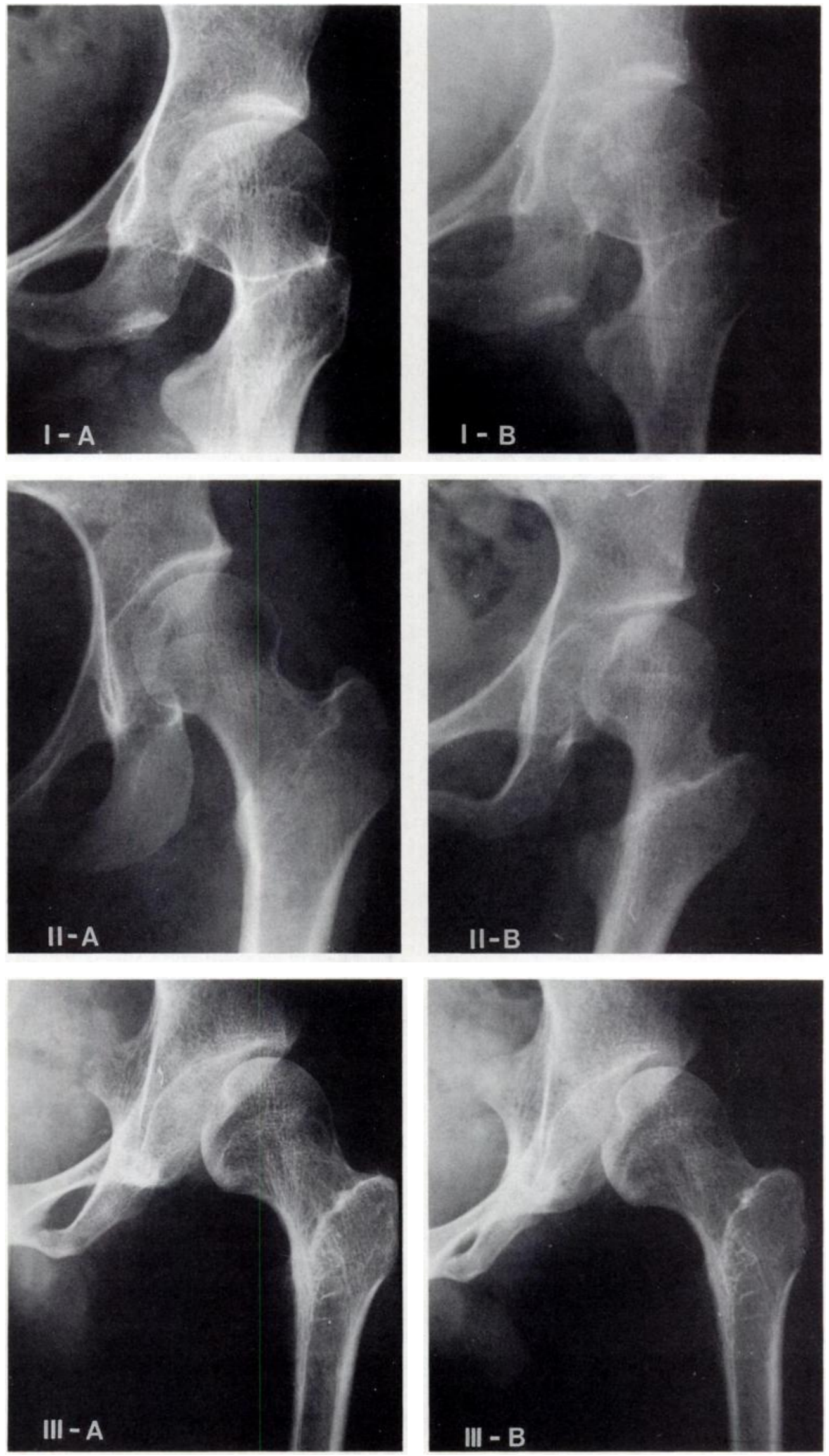

THE JOURNAL OF BONE AND JOINT SURGERY 

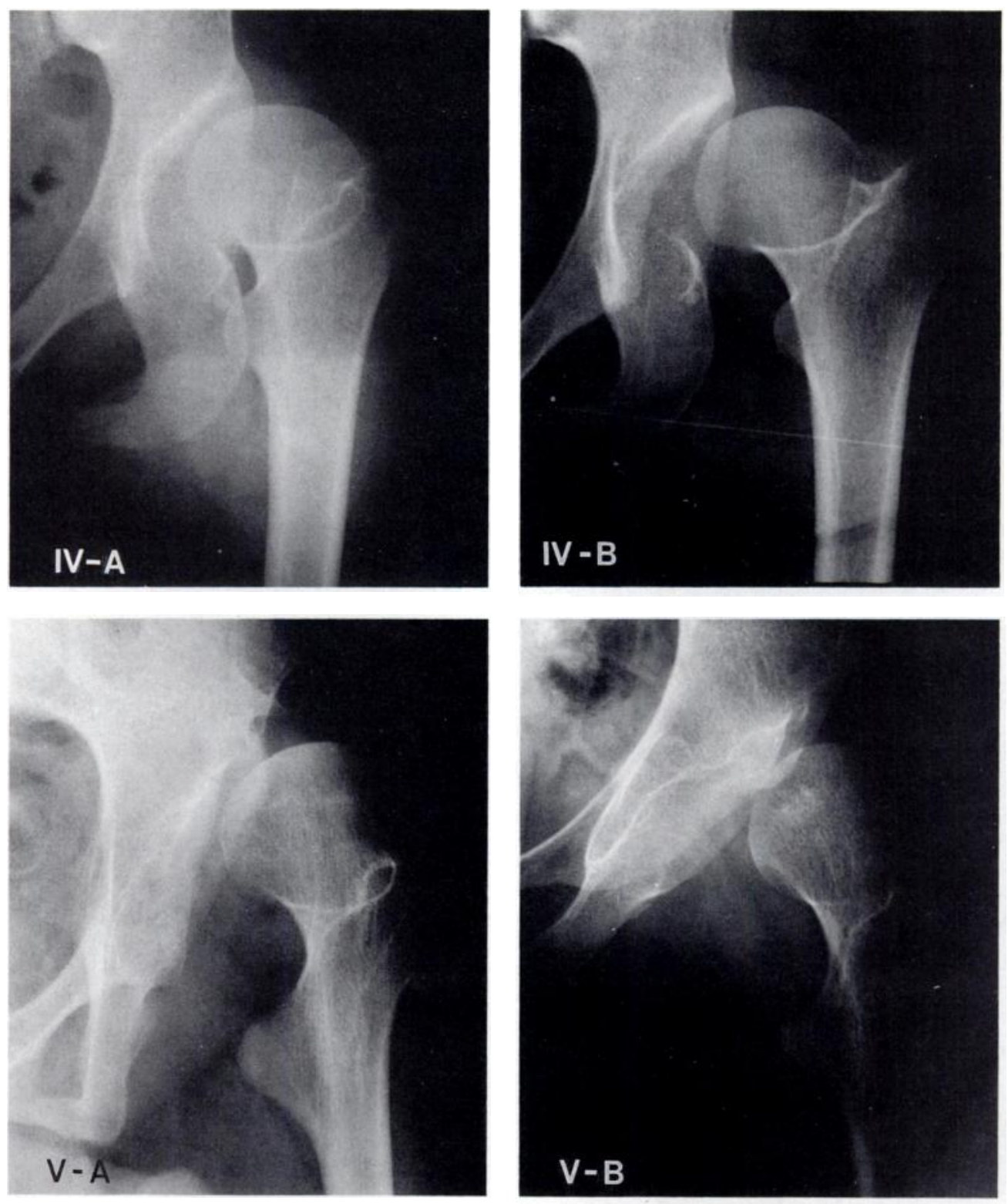

Fig. 2

Examples of the grading system used to record radiographic instability of paralytic hips. For each of grades I to $\mathrm{V}, \mathrm{A}$ is the supine view and $\mathrm{B}$ is a standing view.

the stability of the paralytic hip by combining clinical and radiological criteria. The grades were normal, hypermobile, subluxatable, subluxated, dislocatable, or dislocated. Grade 0 (normal) is a stable hip which is radiologically concentric and congruous. A grade I (hypermobile) hip is stable but has an increased range of motion and radiographic widening of the medial joint space. A grade II (subluxatable) hip allows mild telescoping, and may have a slightly increased acetabular angle (Sharp 1961). A grade III hip is subluxated with a dysplastic acetabulum. A grade IV hip is dislocatable manually and may show a false acetabulum. A grade $\mathrm{V}$ hip is dislocated and usually irreducible. We used this grading system both before and after operation.
Radiology. A standing anteroposterior radiograph of the pelvis was used, unless the patient was unable to stand on both feet, when a recumbent view was taken. The acetabular angle of Sharp (1961), the centre-edge (CE) angle of Wiberg (1939), and the acetabulum-head quotient (Heyman and Herndon 1950) were measured both before and after operation. Transiliac lengthening was measured on a line connecting the centre and summit of the femoral head extended proximally; lengthening was the distance between its intersections with the distal and proximal osteotomy lines (Fig. 3).

Abductor muscle strength. The effect of triple osteotomy on the strength of the abductor muscles was assessed clinically both preoperatively and at review. 


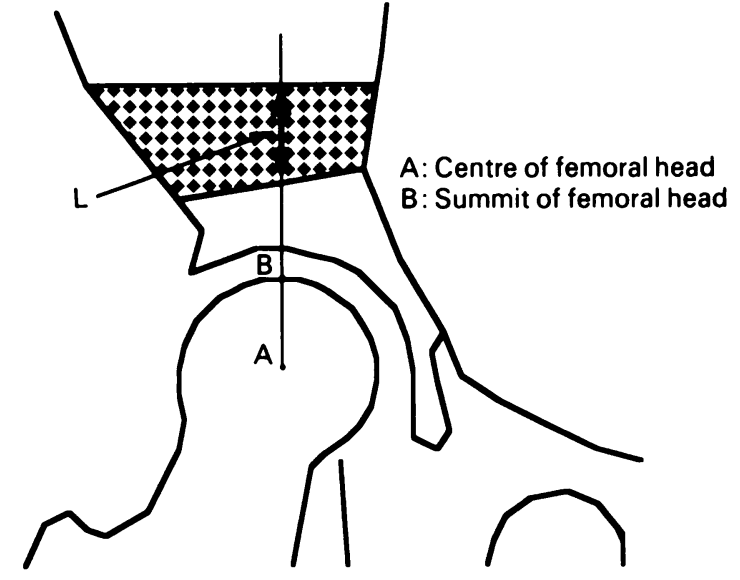

Fig. 3

Measurement of transiliac lengthening. A vertical line is drawn through the centre (A) and summit (B) of the femoral head and extended through the graft. The lengthening $(\mathrm{L})$ is the distance between the distal and proximal osteotomy lines.

Table II. Additional operations in 62 patients on the same side as the triple innominate osteotomy

\begin{tabular}{lc}
\hline Operation & Number \\
\hline Lumbodorsal fasciotomy & 11 \\
Soutter fasciotomy & 7 \\
Campbell operation & 8 \\
Anterior release & 9 \\
Iliopsoas tenotomy & 1 \\
Adductor tenotomy & 3 \\
Open reduction & 3 \\
Shelf operation & 1 \\
Posterior bone block & 1 \\
Femoral derotational osteotomy & 1 \\
Mustard operation & 6 \\
Thomas-Thompson-Straub operation & 5 \\
Combined Thomas-Thompson- & 11 \\
Straub and Ober-Barr operation & 1 \\
\hline Ober-Barr operation &
\end{tabular}

\section{RESULTS}

Hip stability. In the series of 62 paralytic hips before operation, there were 25 grade I, 18 grade II, 10 grade III, six grade IV and three grade $\mathrm{V}$ hips. Of these, 59 hips $(95.2 \%)$ had substantial improvement in stability. All hips of grades I, II and III were converted to grade 0 or I. Two of the six grade IV hips were not improved, and one improved only to grade III. All three grade V hips improved, but one only to grade III. Only four hips had some residual instability (Fig. 4).

Radiology. The mean acetabular angle decreased from $38.7^{\circ}\left(22^{\circ}\right.$ to $\left.60^{\circ}\right)$ to $23.6^{\circ}\left(8^{\circ}\right.$ to $\left.44^{\circ}\right)$, an improvement of

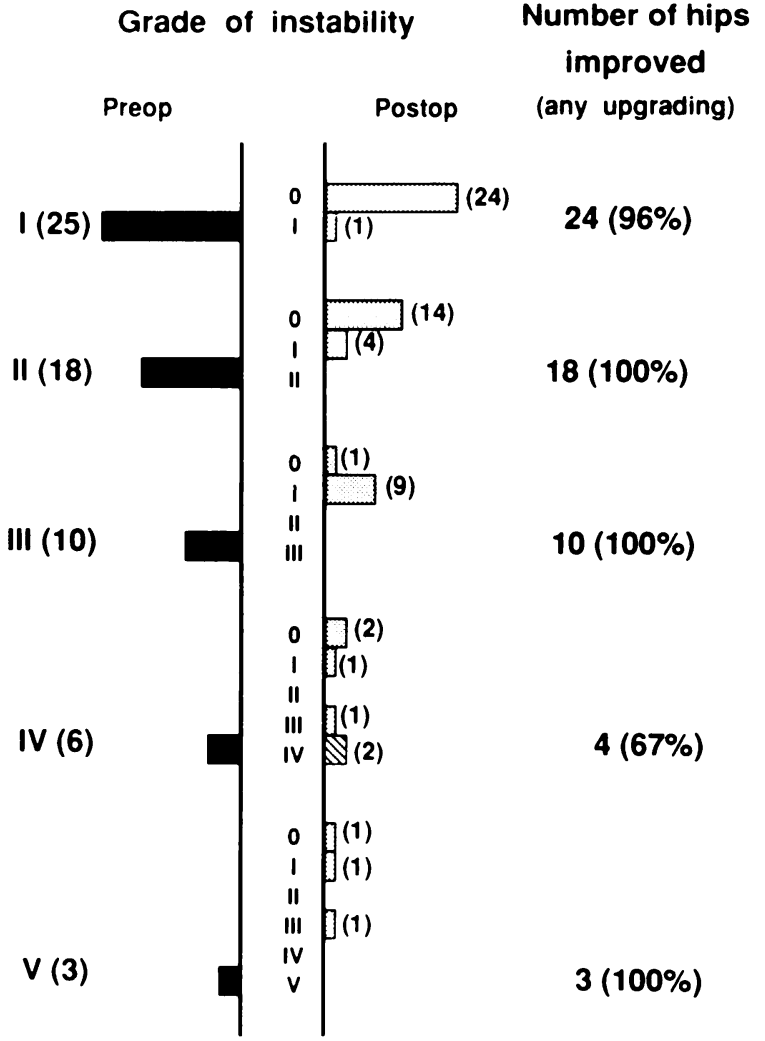

Fig. 4

Grades of instability before and after operation in 62 patients.

$39 \%$. The mean CE angle increased from $17.7^{\circ}\left(-65^{\circ}\right.$ to $40^{\circ}$ ) to $43.8^{\circ}\left(-27^{\circ}\right.$ to $\left.70^{\circ}\right)$, an improvement of $147.5^{\circ}$. The mean acetabulum-head quotient increased from $67.6 \%(0 \%$ to $86.7 \%)$ to $93.5 \%(27 \%$ to $124 \%)$, an improvement of $38.3 \%$ (Fig. 5).

Transiliac lengthening. Excluding three cases in which lengthening was not required, the mean radiological gain in length was $1.7 \mathrm{~cm}(0.6$ to 3$)$. In 21 cases $(33.9 \%)$, after triple osteotomy and soft-tissue correction, the residual inequality was too small to require the femoral lengthening which had originally been planned.

Abductor strength. Twelve of the 39 hips examined $(30.7 \%)$ showed an appreciable improvement in abductor power after osteotomy. The average increase was $0.8(0.3$ to 2 ) on a 0 to 5 grading of strength.

Complications. Five patients had complications: two had femoral nerve palsies, one had both femoral and sciatic palsies. One patient had a soft-tissue infection, and one developed painful degenerative arthritis of the hip (Table III). The nerve palsies were all in the six patients who had the iliopsoas transferred to the greater trochanter at the time of osteotomy. All the nerve palsies had recovered within 15 months.

\section{DISCUSSION}

In Korea there have been no epidemics of acute poliomyelitis since the early 1970 s, and therefore most 

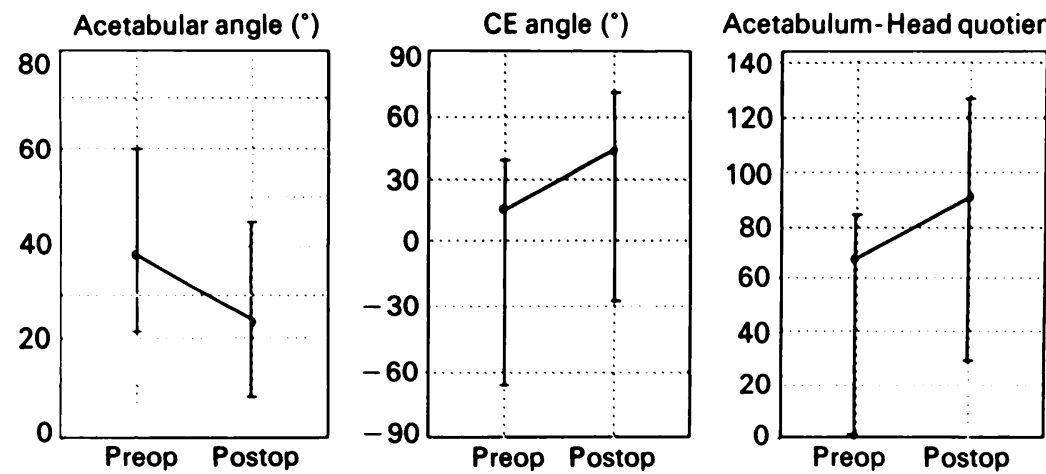

Fig. 5

Mean and range of improvement in three radiological measurements.

poliomyelitic patients are now adults. Our service is one of the few referral centres which treats these patients. Typically, a patient with the late effects of poliomyelitis has complex deformities and a variety of paralyses. A comprehensive approach is required to assess the disabilities and plan treatment, with the aim of improving stability and obtaining a balanced bipedal posture.

We use a staged treatment programme in which deformities of the lower leg are usually corrected first. The correction of deformities and the stabilisation of the foot, ankle and knee are followed by treatment for the hip and pelvis. Abduction contracture of the hip causing pelvic obliquity is first corrected by soft-tissue release. This is particularly important when the ipsilateral limb is longer or when the opposite hip is unstable. Similarly, adductor tenotomy is performed for adduction contracture; this is important when the hip is unstable or when the ipsilateral limb is short. When pelvic obliquity is due to contracture at the iliolumbar angle, often causing a lumbosacral scoliosis, lumbodorsal fasciotomy is performed (Ha et al 1972). This is important if the ipsilateral hip is unstable or the ipsilateral limb is short.

Finally, inequality of leg length is re-evaluated and, provided that the hip is stable, appropriate femoral lengthening is performed. In our society, patients much prefer lengthening to shortening of the longer limb. Equalisation by epiphysiodesis is not possible for our adolescent and adult patients. The age group also means that triple innominate osteotomy is the most effective procedure for correcting acetabular dysplasia and hip instability.

The main aim of triple osteotomy is to provide stability, which is augmented by appropriate soft-tissue releases and motor reconstruction, when such motors are available. Transiliac lengthening at the same operation may render subsequent femoral lengthening unnecessary, but the amount of such lengthening is limited by the fear of nerve palsy. Hip abductor power was increased in many cases, probably due to improved muscle tension and a more stable fulcrum.

Only three of our 62 patients $(4.8 \%)$ failed to gain improved stability, one with grade I and two with grade IV instability. One grade IV hip showed persistent (grade III) subluxation but a subsequent posterior bone block produced a satisfactory final result. Three of the six grade
Table III. Postoperative complications in 62 modified triple innominate osteotomies

\begin{tabular}{lll}
\hline & Number & Percentage \\
\hline Femoral nerve palsy & 2 & 3.2 \\
Femoral and sciatic nerve palsy & 1 & 1.6 \\
Soft-tissue infection & 1 & 1.6 \\
Degenerative arthritis & 1 & 1.6 \\
\hline
\end{tabular}

IV hips showed some residual instability (grade III or IV), and one of the three grade V hips improved only to grade III. The less satisfactory results are probably related to greater preoperative acetabular dysplasia, often with a bicompartmental acetabulum, and more severe motor paralysis.

The gain in length by modification of the innominate osteotomy provides a secondary advantage. Salter has stressed that, in congenital dislocation of the hip, the medial cortices of the ilium should remain in contact to avoid lengthening and undue pressure on the femoral head (Salter 1966; Salter, Hansson and Thompson 1984). After poliomyelitis, however, the hip is often lax and hypermobile, and considerable transiliac lengthening can be achieved safely. We used the trapezoidal iliac strut bone graft described by Millis and Hall (1979) and Barry et al (1992) and achieved a radiological gain in length averaging $1.7 \mathrm{~cm}$. In one case we achieved $3.0 \mathrm{~cm}$ without iliopsoas tenotomy and with no neurological complications.

Millis and Hall (1979) considered that up to $3 \mathrm{~cm}$ could be gained by transiliac lengthening in non-paralytic conditions, but suggested that iliopsoas tenotomy was mandatory to avoid complications due to excess pressure. We found that the paralysed iliopsoas is often attenuated and easily stretched. If some iliopsoas power is present, it is best preserved for its flexor action.

We believe that there are two indications for iliopsoas tenotomy in the paralytic hip. The first is for a grade V (dislocated) hip in which a varus or shortening osteotomy of the femur may be necessary. Iliopsoas tenotomy facilitates reduction, but in such cases unguarded transiliac lengthening may increase the risk of neurological complications.

The second indication is severe flexion deformity 
with a contracted functioning iliopsoas. To avoid neurological complications, it is important that the hip is gradually extended after operation by gentle traction from the Fowler position and not placed in extension in a hip spica cast.

We conclude that triple innominate osteotomy is effective in the management of paralytic and unstable hips in adolescent and adult patients with the sequelae of poliomyelitis. Hip stability is improved, and some lowerlimb lengthening can be achieved. It may also increase abductor muscle power.

The authors gratefully acknowledge the help of Professor Sherman S. Coleman, Salt Lake City, Utah, USA, in reviewing the manuscript.

No benefits in any form have been received or will be received from a commercial party related directly or indirectly to the subject of this article.

\section{REFERENCES}

Barry K, McManus F, O'Brien T. Leg lengthening by the transiliac method. J Bone Joint Surg [Br] 1992; 74-B :275-8.

Eppright RH. Dial osteotomy of the acetabulum in the treatment of dysplasia of the hip. J Bone Joint Surg [Am] 1975; 57-A:1172.

Ha KI, Kim KW, Lee EY, Lee DY, Hahn MS. The role of lumbodorsal fasciotomy in the treatment of paralytic scoliosis and pelvic obliquity. J Korean Orthop Assn 1972; 7:1-8.

Heyman CH, Herndon CH. Legg-Perthes disease: a method for the measurement of the roentgenographic result. J Bone Joint Surg [Am] 1950; 32-A :767-8.

Hopf A. Huftpfannenverlagerung durch doppelte beckenosteotomie zur behandlung der huftgelenksdysplasie und subluxation bei jugendlichen und erwachsenen. $Z$ Orthop 1966; $101: 559-86$.

Kawamura B, Hosono S, Yokogushi K. Dome osteotomy of the pelvis. In: Tachdjian MO, ed. Congenital dislocation of the hip. New York, etc: Churchill Livingstone, 1982:609-23.
Lau JHK, Parker JC, Hsu LCS, Leong JCY. Paralytic hip instability in poliomyelitis. J Bone Joint Surg [ Br] 1986; 68-B:528-33.

LeCoeur P. Correction des défauts d'orientation de l'articulation coxofémorale par osteotomie de l'isthme iliaque. Rev Chir Orthop 1965; $51: 211-2$.

Lee DY. Leg length equalisation by correction of pelvic obliquity and acetabular dysplasia. In: Ueno R, Akamatsu N, Itami Y, Tagawa $\mathrm{H}$, Yoshino S, eds. The hip - clinical studies and basic research. Amsterdam, etc: Excerpta Medica, 1984:373-6.

Millis MB, Hall JE. Transiliac lengthening of the lower extremity: a modified innominate osteotomy for the treatment of postural imbalance. J Bone Joint Surg [Am] 1979; 61-A :1 182-94.

Ninomiya S, Tagawa $H$. Rotational acetabular osteotomy for the dysplastic hip. J Bone Joint Surg [ Am] 1984; 66-A :430-6.

O'Brien JP, Dwyer AP, Hodgson AR. Paralytic pelvic obliquity: its prognosis and management and the development of a technique for full correction of the deformity. J Bone Joint Surg [Am] 1975; 57-A :626-31.

Salter RB. Role of innominate osteotomy in the treatment of congenital dislocation and subluxation of the hip in the older child. $J$ Bone Joint Surg [Am] 1966; 48-A:1413-39.

Salter RB, Hansson G, Thompson GH. Innominate osteotomy in the management of residual congenital subluxation of the hip in young adults. Clin Orthop 1984; 182:53-68.

Sharp IK. Acetabular dysplasia : the acetabular angle. J Bone Joint Surg [Br] 1961 ; 43-B :268-72.

Steel HH. Triple osteotomy of the innominate bone. J Bone Joint Surg [Am] 1973: 55-A :343-50.

Steel HH. Triple osteotomy of the innominate bone: a procedure to accomplish coverage of the dislocated or subluxated femoral head in the older patient. Clin Orthop 1977; 122:116-27.

Tönnis D. Triple osteotomy close to the hip joint. In: Tachdjian MO, ed. Congenital dislocation of the hip. New York, etc: ChurchillLivingstone, 1982:555-65.

Wagner H. Osteotomies for congenital hip dislocation. In: The hip Procs of the 4th meeting of the Hip Society. St Louis, etc: CV Mosby Co, 1976:45-66.

Wiberg G. Studies on dysplastic acetabula and congenital subluxation of the hip joint: with special reference to the complication of osteoarthritis. Acta Chir Scand 1939; 83 :Suppl 58. 